University of Nebraska - Lincoln

DigitalCommons@University of Nebraska - Lincoln

7-31-2005

\title{
Estimated Ultraviolet Radiation Doses in Wetlands in Six National Parks
}

Stephen A. Diamond

U.S. EPA National Health and Environmental Effects Research Laboratory

Peter C. Trenham

University of California

Michael J. Adams

Forest and Rangeland Ecosystem Science Center

Blake R. Hossack

Aldo Leopold Wilderness Research Institute

Roland A. Knapp

University of California Santa Barbara, knapp@lifesci.ucsb.edu

See next page for additional authors

Follow this and additional works at: https://digitalcommons.unl.edu/usgsstaffpub

Part of the Earth Sciences Commons

Diamond, Stephen A.; Trenham, Peter C.; Adams, Michael J.; Hossack, Blake R.; Knapp, Roland A.; Stark, Stacey L.; Bradford, David; Corn, P. Stephen; Czarnowski, Ken; Brooks, Paul D.; Fagre, Dan; Breen, Bob; Detenbeck, Naomi E.; and Tonnessen, Kathy, "Estimated Ultraviolet Radiation Doses in Wetlands in Six National Parks" (2005). USGS Staff -- Published Research. 98.

https://digitalcommons.unl.edu/usgsstaffpub/98

This Article is brought to you for free and open access by the US Geological Survey at DigitalCommons@University of Nebraska - Lincoln. It has been accepted for inclusion in USGS Staff -- Published Research by an authorized administrator of DigitalCommons@University of Nebraska - Lincoln. 


\section{Authors}

Stephen A. Diamond, Peter C. Trenham, Michael J. Adams, Blake R. Hossack, Roland A. Knapp, Stacey L. Stark, David Bradford, P. Stephen Corn, Ken Czarnowski, Paul D. Brooks, Dan Fagre, Bob Breen, Naomi E. Detenbeck, and Kathy Tonnessen 


\title{
Estimated Ultraviolet Radiation Doses in Wetlands in Six National Parks
}

\author{
Stephen A. Diamond, ${ }^{1 *}$ Peter C. Trenham, ${ }^{2}$ Michael J. Adams, ${ }^{3}$ \\ Blake R. Hossack, ${ }^{4}$ Roland A. Knapp, ${ }^{5}$ Stacey L. Stark, ${ }^{6}$ David Bradford, ${ }^{7}$ \\ P. Stephen Corn, ${ }^{4}$ Ken Czarnowski, ${ }^{8}$ Paul D. Brooks, ${ }^{9}$ Dan Fagre,${ }^{10}$ \\ Bob Breen,${ }^{12}$ Naomi E. Detenbeck, ${ }^{1}$ and Kathy Tonnessen ${ }^{12}$
}

\begin{abstract}
${ }^{1}$ Office of Research and Development, U.S. EPA National Health and Environmental Effects Research Laboratory, Duluth, Minnesota 55804, USA; ${ }^{2}$ Section of Evolution and Ecology, University of California, Davis, California 95616, USA; ${ }^{3}$ Forest and Rangeland Ecosystem Science Center, U.S. Geological Survey, Corvallis, Oregon 97331, USA; ${ }^{4}$ Northern Rocky Mountain Science Center, Aldo Leopold Wilderness Research Institute U.S. Geological Survey, Missoula, Montana 59807, USA; ${ }^{5}$ Sierra Nevada Aquatic Research Laboratory, University of California, Crowley Lake, California 93546, USA; ${ }^{6}$ Department of Geography, University of MinnesotaDuluth, Duluth, Minnesota 55804, USA $;^{7}$ Office of Research and Development, U.S. EPA National Exposoic Research Laboratory, Las Vegas, Nevada 89193-3478, USA; ${ }^{8}$ Rocky Mountain National Park, National Park Service, Este Park, Colorado 80517, USA;

${ }^{9}$ Hydrology and Water Resources, University of Arizona, Tucson, Arizona 84716, USA; ${ }^{10}$ Glacier Field Station, Northern Rocky Mountain Science Center U.S. Geological Survey, West Glacier, Montana 59936, USA; ${ }^{11}$ Acadia National Park, National Park Service, Bar Harbor, Maine 04609, USA; ${ }^{12}$ Rocky Mountains Cooperative Ecosystems Studies Unit, National Park Service and (CESU), School of Forestry, University of Montana, Missoula, Montana 59812, USA
\end{abstract}

\begin{abstract}
Ultraviolet-B radiation (UV-B, 280-320-nm wavelengths) doses were estimated for 1024 wetlands in six national parks: Acadia (Acadia), Glacier (Glacier), Great Smoky Mountains (Smoky), Olympic (Olympic), Rocky Mountain (Rocky), and Sequoia/ Kings Canyon (Sequoia). Estimates were made using ground-based UV-B data (Brewer spectrophotometers), solar radiation models, GIS tools, field characterization of vegetative features, and quantification of DOC concentration and spectral absorbance. UV-B dose estimates were made for the summer solstice, at a depth of $1 \mathrm{~cm}$ in each wetland. The mean dose across all wetlands and parks was $19.3 \mathrm{~W}-\mathrm{h} \mathrm{m}^{-2}$ (range of 3.4-32.1 W-h m $\mathrm{m}^{-2}$ ). The mean dose was lowest in Acadia (13.7 W-h $\mathrm{m}^{-2}$ ) and highest in Rocky $\left(24.4 \mathrm{~W}-\mathrm{h} \mathrm{m}^{-2}\right)$. Doses were significantly different among all parks. These wetland doses correspond to UV-B flux of $125.0 \mu \mathrm{W}$

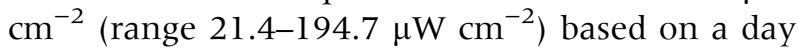

Received 3 March 2003; accepted 3 October 2003; published online 31 July 2005.

*Corresponding author; e-mail: diamond.steve@epa.gov length, averaged among all parks, of $15.5 \mathrm{~h}$. Dissolved organic carbon (DOC), a key determinant of water-column UV-B flux, ranged from 0.6 (analytical detection limit) to $36.7 \mathrm{mg} \mathrm{C} \mathrm{L}^{-1}$ over all wetlands and parks, and reduced potential maximal UV-B doses at $1-\mathrm{cm}$ depth by $1 \%-87 \%$. DOC concentration, as well as its effect on dose, was lowest in Sequoia and highest in Acadia (DOC was equivalent in Acadia, Glacier, and Rocky). Landscape reduction of potential maximal UV-B doses ranged from zero to $77 \%$ and was lowest in Sequoia. These regional differences in UV-B wetland dose illustrate the importance of considering all aspects of exposure in evaluating the potential impact of UV-B on aquatic organisms.

Key words: ultraviolet radiation; DOC; UV-B; amphibians; national parks.

\section{INTRODUCTION}

The need for an accurate estimation of ultraviolet-B radiation (UV-B; wavelengths from $280 \mathrm{~nm}$ to 320 
$\mathrm{nm}$ ) exposure has grown tremendously over the last several decades, due primarily to the photochemical reduction of stratospheric ozone by anthropogenic chlorofluorocarbons. Because ozone strongly absorbs UV-B, its reduction can dramatically increase the flux of UV-B that reaches the earth's surface. Although the release of ozonedamaging compounds has been greatly reduced, their effect on stratospheric ozone is presently at its maximum and will diminish only slowly over the next several decades (UNEP 1998). This suggests that biological responses to elevated UV-B may also continue for some time. These responses include increases in rates of skin cancers, ocular damage, and immunosuppression in humans, and direct mortality, DNA and membrane damage, inhibition of photosynthesis, mutation, and malformation in nonhuman taxa (Young and others 1993). The continued elevated UV-B exposure and the potential for significant biological effects suggest a significant need for exposure estimation in a variety of habitats, including aquatic systems.

Estimation of UV-B exposure for any location or organism involves incorporating several factors that affect UV-B flux. These include time, location, atmospheric transfer of solar radiation reaching the top of the earth's atmosphere, weather conditions, and elevation of the horizon in the local landscape (by either vegetative, topographic, or man-made features), and in aquatic systems, reflection from the water surface and propagation of radiation within the water column (Madronich 1993; Blumthaler and others 1994; Jerome and Bukata 1998; Laurion and others 2000; Diamond and others 2002). Under cloudless conditions, UV-B exposure approximates a Gaussian distribution when UV-B flux is plotted against time of day, and daily dose is the integrated area under the curve. Under these conditions the maximum flux of UV-B at any moment can be calculated using simple trigonometric functions that describe angle of incidence and atmospheric pathlength (Robinson 1966; Madronich and Flocke 1997). These maxima are reduced by increased cloud cover or the presence of UV-absorbing particles and aerosols in the atmosphere.

Ultraviolet-B dosimetry is complicated at many locations by elevation of the local horizon by landscape features, both topographic and vegetative, that can significantly diminish the amount of UV-B reaching the earth's surface and the surface of wetlands (Grant 1991; Dubayah 1994; Dubayah and Rich 1995; Parsons and others 1998; Parisi and others 2000). These landscape features reduce UVB dose by casting shadows and by obscuring portions of the sky from which diffuse radiation is re- ceived (Grant 1991; Dubayah 1994; Dubayah and Rich 1995; Parsons and others 1998; Parisi and others 2000). If any portion of the $360^{\circ}$ hemisphere (sky view) over a location is obscured by features within the local landscape, total irradiance, and UV-B dose, will be reduced. The reduction is relatively greater if direct irradiance is blocked and smaller if diffuse irradiance is blocked. These factors are quantitatively difficult to incorporate into dose estimation or to quantify when they contribute to measurements made at specific locations and times. Recently, however, software tools have been developed that combine sophisticated irradiance models with Geographic Information Systems (GIS) data to incorporate terrain features into UV-B dose estimation (Hetrick and others 1993; Dubayah 1994; Rich and others 1995; Dubayah and Rich 1995, 1996).

Several additional factors influence UV-B dosimetry in the aquatic environment. In general, approximately $5 \%-8 \%$ of surface radiation is reflected by the surface of the water (Jerlov 1976; Green and Shippnick 1982; Jerome and others 1988; Jerome and Bukata 1998). Within the water column, suspended organic and inorganic material, algae, and, most importantly, dissolved organic carbon (DOC) can contribute significantly to attenuation (Morris and others 1995; Williamson and others 1996; Morris and Hargreaves 1997; Crump and others 1998; Jerome and Bukata 1998; Smith and others 1999; Laurion and others 2000). Pure water contributes only slightly to attenuation (Karentz and Lutz 1990; Kirk 1994; Laurion and others 1997).

Recently, increasing UV-B exposure has been hypothesized as a cause of observed declines and malformations in populations of many amphibian taxa (Blaustein and others 1994a, Kiesecker and Blaustein 1995; Blaustein and others 1997; Nagl and Hofer 1997; Ankley and others 1998, 2000, 2002; Hader and others 1998; Pounds 2001; Tietge and others 2001; 1994b; Palen and others 2003). This is a particularly tenable hypothesis for several reasons, including the correspondence between the recent increase in UV-B flux and field observations of effects in amphibians, the global distribution of both phenomena, and the potential for relatively high UV exposure of many amphibians.

In this article we present single-day UV-B dose estimates for 1024 wetlands in six National Parks in the United States: Acadia (Acadia; Maine), Glacier (Glacier; Montana), Great Smoky Mountains (Smoky; Tennessee, and North Carolina), Olympic (Olympic; Washington), Rocky Mountain (Rocky; Colorado), and Sequoia/Kings Canyon (Sequoia; 
California, including the adjacent John Muir Wilderness). The primary goal of this effort was to provide consistent, comparable, UV-B exposure estimates for preliminary statistical analyses of the relationship between typical UV-B exposure and amphibian distributions (Adams and others, this issues). Additionally, these estimates can be used to compare differences in UV exposure across regions and landscapes, to estimate the relative importance of landscape features and DOC in determining exposure levels within wetland water columns, and to define wetland areas or specific wetlands where amphibians and other species are at greatest risk for UV effects.

It should be noted that the UV-B dose values presented here are intended to be first approximations; it was not our intent, and beyond the scope of this research, to develop extensive optical models for the estimation of UV-B doses in wetlands. At the present time, the capacity to measure daily UV-B doses in situ in even a few wetlands is severely limited by instrument accuracy and availability and the numerous logistical considerations associated with continuously monitoring solar radiation at field sites. Without such data, estimation of the uncertainty associated with these UV-B dose estimates is not possible. Previous to this work, estimates of UV dose in amphibian research (except Diamond and others 2002) has been generally limited to single measurements of UV flux or, at most, measurements of flux made once per day during experiments. This limits both the accuracy of experimental dose estimates (these are often not presented) and the ability to evaluate how local exposure compares to potential exposure at other locations. Despite the limitations of the dose estimates presented here, they represent both an advance in attempts to estimate UV dose and also provide a framework which can be used to advance the science of field UV dosimetry.

\section{MeThoDS}

\section{Dosimetry Overview}

Estimations of UV-B dose were made for a single day, the summer solstice, at a depth of $1 \mathrm{~cm}$ in each wetland (Figure 1). The summer solstice was selected because it is a notable astronomical event that marks midsummer and is near the midpoint of the reproductive season for the range of amphibian taxa that occur across North America. The 1-cm depth was selected because it corresponds to the 1$\mathrm{cm}$ pathlength used in laboratory absorbance measurements and, although it may not directly

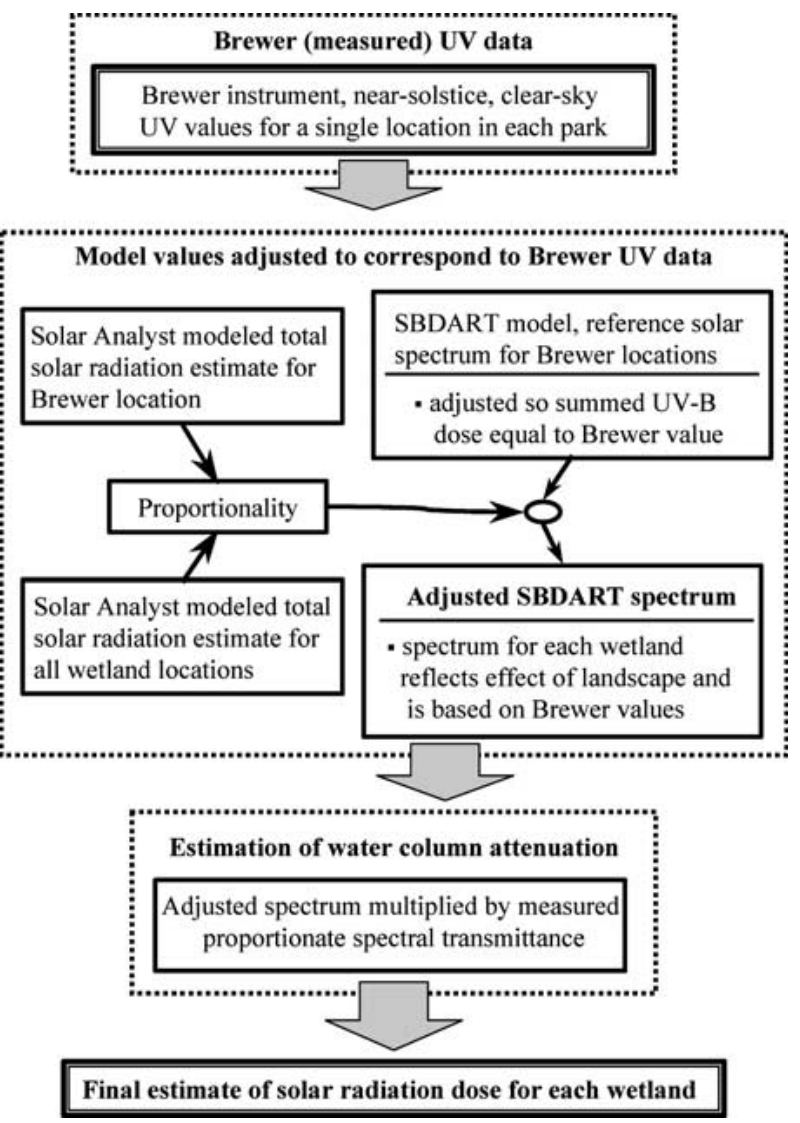

Figure 1. Flowchart depicting steps used in estimating UV dose in all studied wetlands.

represent egg and larval stage exposure depths for all species, it does serve as a consistent reference dose for relating UV-B exposure to species distributions among wetlands.

In brief (details below), the steps involved in UV$\mathrm{B}$ dose estimates are outlined below:

1. Estimates of UV-B dose were based on groundlevel, hourly UV-B (280-320 nm wavelengths) data collected by Brewer spectrometers from 1997 to 2003 at a single location in each National Park (see http://www.epa.gov/uvnet/). These data were analyzed to determine the average of the highest 95th centile of UV-B doses. This value is an estimate of the maximal clear-sky dose typical of each Brewer location.

2. A GIS-based solar radiation model, Solar Analyst (HEMI, Los Alamos, NM), was used to estimate total solar radiation dose $(300-3000 \mathrm{~nm})$ for each Brewer location and for each studied wetland. Solar Analyst was used to incorporate the effect of topographic and vegetative features on solar radiation dose in the vicinity of the Brewer and wetland locations. The Solar Ana- 
Table 1. Description of study locations and years of sampling.

\begin{tabular}{|c|c|c|c|c|c|c|}
\hline & \multicolumn{6}{|c|}{ National Park } \\
\hline & Acadia & Glacier & Smoky & Olympic & Rocky & Sequoia \\
\hline Day length (hr) & 16.2 & 15.2 & 14.8 & 15.7 & 14.7 & 16.3 \\
\hline Mean elevation (m) & 15 & 1555 & 783 & 430 & 2600 & 2422 \\
\hline Sampling years & $\left({ }^{\prime} 00\right)$ & $\left(' 99,{ }^{\prime} 00\right)$ & $\left({ }^{\prime} 00\right)$ & $\left(' 99,,^{\prime} 00\right)$ & $(' 99, ' 00)$ & $\left({ }^{\prime} 00,,^{\prime} 01\right)$ \\
\hline$N$ & $(53)$ & $(96,387)$ & (13) & $(96,147)$ & $(25,43)$ & $(23,122)$ \\
\hline
\end{tabular}

lyst dose estimated for each wetland was divided by the dose estimated for the park Brewer location to derive a proportionality factor that represented the relative effect of landscape.

3. A second solar radiation model, SBDART [Santa Barbara DISORT (Discrete Ordinate Radiative Transfer) Atmospheric Radiative Transfer; http://www.crseo.ucsb.edu/esrg/pauls_dir/], was used to generate a solar spectrum (comprising flux values for each nanometer of wavelength from 280 to $3000 \mathrm{~nm}$ ) for each Brewer location. These spectra were adjusted so that the energy present was representative of the maximal daily dose derived from the Brewer location data. The spectrum was then multiplied by the proportionality factor calculated from the Solar Analyst values. The result was a spectrum comprising flux values in $1-n m$ increments, from 280 to $700 \mathrm{~nm}$, representing the average spectral flux for the summer solstice at the surface of each wetland.

4. The spectra were reduced by $6.5 \%$ to account for surface reflection. Water-column attenuation was incorporated by multiplying the spectrum for each wetland by the proportionate transmittance derived from laboratory scans of water samples collected from each wetland. The final solar spectrum was an estimate of the average solar radiation flux on the summer solstice, at a depth of $1 \mathrm{~cm}$ in each wetland.

5. Finally, UV-B doses were calculated by integrating each spectrum from 280 to $320 \mathrm{~nm}$ and multiplying by the length of day for the summer solstice at each location.

\section{Wetland Selection and Sampling}

Wetlands were selected to encompass a large range of elevation and habitat or drainage type, to maximize the number of wetlands that could be visited within each drainage basin, and to maximize the potential number of amphibian species present.
The majority of studied wetlands were remote from human activity, generally distant from roads, and accessible only by backpacking except, in some cases, in the more urban parks; Smoky and Acadia. All field measurements and collection of water samples occurred between March and September in 1999, 2000, and 2001, although not all parks were sampled in all years (Table 1). The earliest sampling dates generally corresponded to the earliest breeding times for amphibians. The logistics of visiting these wetlands, many of which are accessible only by backpacking, precluded careful matching of sampling dates with periods of maximal breeding for the species present. The uncertainty in dose estimation introduced by variation in sampling time is largely due to intra and interannual variation in DOC concentration and composition (See Brooks and others, this issue), and is discussed in later sections of this article.

\section{Calculation of UV-B Dose}

Estimation of solar radiation doses in aquatic systems involves two steps. The first is estimation of local terrestrial dose (this is also the surface-of-thewater dose) that incorporates the effect of location (latitude, longitude, and elevation), specific date/ time and duration to be considered, atmospheric attenuation, and landscape (topography or vegetation) effects. The second step involves estimating the effect of water surface reflection and quantifying, on a spectral basis, the attenuation of solar radiation by the wetland water column. Although a range of dissolved and suspended components can contribute to wetland-specific attenuation, the most consistent predictor is DOC (Peterson and others 2002; Morris and others 1995). The processes and methods used for these two dose-estimation steps are described below.

The initial terrestrial component of UV-B dose in each wetland was derived using UV-B data available from the United States Environmental Pro- 
tection Agency (EPA) and the University of Georgia (UGA) (see http://www.epa.gov/uvnet/ and Saber and others 2000); a GIS-based, broadband solar radiation software package, Solar Analyst (HEMI, Los Alamos, NM); and a spectral solar radiation and radiative transfer model, SBDART [Santa Barbara DISORT (Discrete Ordinate Radiative Transfer) Atmospheric Radiative Transfer; http:// www.crseo.ucsb.edu/esrg/pauls_dir/]. The EPA/ UGA data used are daily UV-B doses estimated from hourly measurements made using Brewer spectrophotometers during the years 1997-2001. The Brewer instruments are permanently located in each of the studied national parks. Values used in dose estimation for this study were Diffey doses, an estimate of the potential for erythema (McKinlay and Diffey 1987; Diffey 1995). Brewer data were analyzed to identify the highest 95th centile of Diffey daily doses for each park between June 6 and July 4, a period representing four weeks spanning the summer solstice. The final Brewersite dose value in subsequent calculations was the average of the derived 95th centile. This value is an estimate of the maximal clear-sky dose typical of each Brewer location.

Solar Analyst was used to quantify the effect of landscape features on solar radiation dose. This process involved computation of direct and diffuse irradiance at the surface of each wetland and at the Brewer instrument location based on topographic information available in United States Geological Survey (USGS) Digital Elevation Model (DEM). The model generates a hemispherical viewshed (that is, a $360^{\circ}$ hemispherical fish-eye view of the sky) in which mountains, ridges, or other topographic features that obscure portions of the sky are identified, as well as a sunmap that represents the flux of direct and diffuse irradiance from each sector of the sky. The sunmap is then overlaid with the viewshed and irradiance is reduced in sky sectors where the sky view is obstructed. For example, if a wetland is situated directly east of a large north-south ridge, during midsummer it may be completely shaded, for the majority of the afternoon. The resulting reduction in both direct and diffuse irradiance from the sky sectors obscured by the ridge is then incorporated into a daily solar radiation dose. This is a critical component of UV-B dose estimation, as shading by such features can significantly reduce incoming solar radiation. The effect of large, potentially shading, vegetative features was incorporated into Solar Analyst modeling by generating surrogate elevations based on field measurement of the inclination angle for vegetative features in the landscape. These data were transformed into sur- rogate azimuth and elevation values which were then integrated into the DEM. This manipulation of DEMs incorporated the shading effect of vegetative features; Solar Analyst derived their effects as though they were topographic features. Solar Analyst was configured to produce a clear-sky solar radiation (300-3000 nm) dose for each wetland, and for the Brewer locations, for the summer solstice (June 21 ) by integrating hourly model runs over the duration of the day. These standardized conditions yielded a dose value that was directly comparable among wetlands and Brewer sites. A proportionality value was then calculated for each wetland location relative to the Brewer site in each park. This proportionality was ultimately applied to the modeled solar spectrum developed (described below) for the Brewer location in each park.

Solar Analyst computes only total (broad waveband) solar radiation (300-3000-nm wavelengths) values. To derive UV-B and a full solar spectrum, an additional model, SBDART (Ricchiazzi and others 1998), was employed. This software tool calculates solar irradiance for any location and time and greatly simplifies the incorporation of complex atmospheric variables and surface albedo (reflection from earth surfaces) by allowing the operator to select from several standard atmospheres and surface properties. These standard atmospheres and albedos incorporate values for temperature, pressure, water vapor, aerosols, typical particulate components, and land cover ("vegetation" was selected for this research). The U.S. Standard Atmosphere 1962 (U.S. standard Atmosphere 1976) was used in all modeling. Ozone, the most critical clearsky atmospheric determinant of surface UV-B irradiance, was set to 300 Dobson Units (the global average). As implemented in this study, output from the SBDART model included irradiance values, in l-nm increments, calculated hourly over the duration of the summer solstice for clear-sky conditions for each Brewer location. The hourly spectra produced by SBDART were then averaged for each wavelength. The resulting spectral data were multiplied by the proportion value calculated for each wetland relative to the Brewer location. The resulting solar spectrum represents the average water-surface spectral flux for each wetland. A more thorough description of the DISORT model and the standard atmospheres used in SBDART, as well as the design and function of the SBDART model, is available elsewhere (Ricchiazzi and others 1998; Stamnes and others 1988; Robinson 1966).

To account for water-column attenuation, output from the spectrophotometric absorbance scans completed on each wetland water sample (collec- 
tion described below) was converted into wavelength-specific proportionate transmittance (Rostan and Cellot 1995). Each wetland water-surface solar spectrum was then multiplied by these proportionate transmittance values. The product was a solar radiation spectrum reduced by absorbance of radiation in the $1-\mathrm{cm}$ water column present in the spectrometer cuvette. Spectra were also reduced by $6.5 \%$ to account for surface reflectance (Jerlov 1976; Green and Shippnick 1982; Jerome and others 1988; Jerome and Bukata 1998). Biological weighting function (BWF: the wavelength-specific potential for biological damage) doses for DNA damage (Setlow 1974), erythema (McKinlay and Diffey 1987; Diffey 1995), and inhibition of photosynthesis (Baucher and Prezelin 1996) were calculated by multiplying the $1-\mathrm{cm}$ spectrum by effectiveness values for each weighting function. The general equation for dose calculations is

$$
\text { dose }=\int_{h_{1}}^{h_{1}} \int_{\lambda_{1}}^{\lambda_{i}} \operatorname{BWF}(\lambda) I(\lambda) d(\mathrm{~h})
$$

where $h$ is duration of daylight hours, $\lambda$ is all applicable wavelengths, and $I$ is spectral irradiance derived as discussed above. Doses not based on BWFs were calculated using this general equation with the factor for BWF removed. Weighting functions were normalized to an effectiveness of 1 at the lowest wavelength originally tested. Final values for UV-B, UV-A, and visible radiation flux, as well as the three BWFs, were obtained by summation of intensities across appropriate wavelengths. These flux values were converted to doses by multiplying each by the duration (h) of daylight for the summer solstice for the Brewer location in each park.

\section{Estimation of Vegetative Effects}

The elevation of vegetative features at each wetland was recorded using a viewfinder clinometer. The angle of inclination to the highest point of vegetative features was measured at $20^{\circ}$ azimuth increments, and then trigonometrically transformed into elevations at a distance of $300 \mathrm{~m}$ from the wetland. The azimuth and elevation values were then transformed into $x, y, z$ coordinates for incorporation into DEMs. No effort was made to account for variability in the density of vegetative features.

\section{Collection and Analysis of Water Samples}

Water samples (generally, one per wetland) were collected at the north side of each wetland, from at least $10 \mathrm{~cm}$ below the water surface in at least $0.5-\mathrm{m}$ depth, filtered on-site through $0.07-\mu \mathrm{m}$ ashed glass fiber filters (GF-F, Gelman, Inc., Ann Arbor, MI), and transported in ashed amber glass bottles at ambient temperature. Refrigeration was not possible because of the remote nature of many of the study sites; however, great care was taken to keep samples as cool as possible. All samples were received in the laboratory within ten days of sampling and were stored at $4^{\circ} \mathrm{C}$ until analysis. All samples were analyzed within three weeks of collection. The spectral transmittance characteristics of water samples were quantified in one-nm increments using a bench-top scanning spectrometer (Perkin Elmer Lambda 20, Perkin Elmer, Norwalk, CT). DOC concentrations were measured using a combustion method (Dohrmann DC 190 Carbon Analyzer, Tekmar-Dohrman, Cincinnati, $\mathrm{OH}$ ). Spectrophotometric data were expressed as proportionate transmittance for use in dose calculations.

\section{In situ Water-Column UV Attenuation}

Water-column UV attenuation was also estimated based on in situ measurements of underwater UV levels, where possible. Because these estimates are accurate only when data are collected on relatively cloud-free days, it was expected that they would not be obtainable for many of the visited wetlands. However, where available, such estimates provide for comparison with other studies. Underwater solar radiation data were collected using a Macam radiometer (model UV-203-IP-67, Advanced Photonics International, New York NY) by measuring UV-B, UV-A, and visible irradiance at a minimum of 6 depths in each wetland, including an abovesurface measurement (Peterson and others 2002). Three replicate data sets were generally collected for each waveband and all measurements where done within approximately two hours of solar noon and only during periods of stable light (that is, clouds did not obscure the sun during data recording). Attenuation coefficients $\left(K_{\mathrm{d}}\right.$, field $)$ were estimated using:

$$
K_{d, \text { field }}=\frac{\ln \left[E_{0} / E_{Z}\right]}{\Delta_{z}}
$$

where $E_{0}$ and $E_{Z}$ are irradiance measured just below the water surface and at various depths $(Z$, in meters).

Attenuation calculations were initially completed on all replicates separately. Where $r^{2}$ values for the regression were less than $<0.85$, the data were examined graphically and clearly inconsistent 
data were discarded. The most common inconsistency arose when light levels changed during data collection. This is readily apparent in the data when higher intensities are measured at greater depths; this occurs when the solar disk is obscured by haze or clouds during measurement of flux at shallower depths in the same attenuation replicate. Once anomalous regressions had been examined, slopes were determined on all replicate samples for each bandwidth.

Attenuation was also quantified as $\mathrm{K}_{\mathrm{d}}$, lab using UV-B flux at depths of zero and $0.01 \mathrm{~m}$ (corresponding to the $1-\mathrm{cm}$ cuvette pathlength used in spectrophotometric scans). The UV-B flux values were derived based on the solar spectra developed for each wetland and the $\mathrm{K}_{\mathrm{d} \text {,field }}$ equation described above.

\section{Spatial and Temporal Variability in Dose Estimates}

Dose estimates differ among wetlands due to geographic location, effects of landscape, and differences in the attenuation characteristics of DOC. Among these differences the effects of location and landscape are the most predictable as they are subject to little alteration (at least in these national park wetlands). The differences in the effect of DOC on UV doses are more difficult to quantify because DOC often varies over time, and wetland sampling dates ranged over 6-month periods and over three years. To characterize the variability in DOC effect on dose, several wetlands were sampled multiple times during each year. In addition, several wetlands were also sampled in two separate years, but on similar dates.

\section{Data Analyses}

Differences between parks in wetland UV-B doses, DOC concentrations, and the effect of landscape and DOC on UV-B were examined using analysis of variance (ANOVA) with means comparisons. Where analyses involved the use of proportion values, these were arc-sine transformed prior to ANOVA. The relationship of DOC concentration and the rate at which UV-B is attenuated (attenuation coefficients estimated from laboratory spectrophotometric scans) were expressed as regressions, and significant differences among parks were examined by comparing the regression slope parameters for all pairwise combinations of parks. Comparisons of year-to-year variation were expressed graphically. All statistical analyses and summarizations were completed using SAS (SAS Institute, Cary, NC) statistical software.

\section{Results}

Ultraviolet radiation (UV-B) flux and dose were estimated in 1024 wetlands in six national parks in 1999, 2000, or 2001 (Table 2). UV-B doses ranged from 3.4 to $32.1 \mathrm{~W}-\mathrm{h} \mathrm{m}^{-2}$. The Mean dose across all wetlands and parks was $19.39 \mathrm{~W}-\mathrm{h} \mathrm{m}^{-2}$ $(\mathrm{SD}=5.65)$. Based on a mean day length of $15.5 \mathrm{~h}$, this dose corresponds to a flux of $125.6 \mu \mathrm{W} \mathrm{cm}{ }^{-2}$ $(\mathrm{SD}=21.49)$ and a range of 21.53 to $195.72 \mu \mathrm{W}$ $\mathrm{cm}^{-2}$. ANOVA revealed significant differences in wetland UV-B doses between parks $(F=197.9, P<$ 0.0001 ). Means tests (Duncan's multiple range test, with control for comparison-wise error rate) indicated that wetland UV-B dose was dissimilar among all parks. DOC concentrations ranged from 0.6 (analytical detection limit) to $36.7 \mathrm{mg} \mathrm{C} \mathrm{L}^{-1}$ over all parks. ANOVA revealed significant differences in DOC concentration between parks $(F=16.4, \quad P<0.0001)$. Means tests (Duncan's multiple range test, with control for comparisonwise error rate) indicated that wetland DOC concentration was similar in Glacier, Acadia, and Rocky, and in Smoky and Olympic. These two groups were dissimilar from one another. Sequoia wetland DOC concentrations were dissimilar from those in all other parks. The mean DOC concentration was lowest for Sequoia at $1.81 \mathrm{mg} \mathrm{C} \mathrm{L}^{-1}$ $(\mathrm{SD}=1.54)$ and ranged from 3.64 to $7.95 \mathrm{mg} \mathrm{C} \mathrm{L}^{-1}$ for the other five parks.

Generally, the distributions of UV-B doses among all wetlands in each park appear similar (Figure 2), except that the eastern parks, Acadia and Smoky, have higher frequencies of wetlands at relatively lower doses. Dose estimates are available for two years of sampling in the western parks; both years are illustrated for these parks in Figure 2 and indicate generally consistent frequency distributions among years. It should be noted that, except for Glacier, different wetlands were sampled from year to year.

The effect of landscape (location and obstruction of the sky view by either geographic or vegetative features) on UV-B dose (Table 2) was differentiated from the effect of DOC by normalizing UV-B doses to the maximum value in each park. The maximum value was used, rather than the Brewer site value, because in all of the western parks there were wetland sites where the dose estimate exceeded that for the Brewer location (due to elevation and landscape effects). Among all parks and wetlands, landscape reduced the possible maximum terrestrial UV-B dose by zero to $77 \%$. The mean reduction due to landscape for each park ranged from $5.9 \%$, in Sequoia, to $31.4 \%$, in Smoky and was 
Table 2. Summary Statistics for Factors Incorporated into Estimation of UV-B Dose and Flux

\begin{tabular}{|c|c|c|c|c|c|c|}
\hline & \multicolumn{6}{|c|}{ National Park } \\
\hline & Acadia & Glacier & Smoky & Olympic & Rocky & Sequoia \\
\hline \multicolumn{7}{|l|}{ (Diffey, $\mathrm{J} \mathrm{m}^{-2}$ ) } \\
\hline SD & 211.3 & 243.1 & 328.0 & 274.9 & 325.1 & 169.5 \\
\hline$N$ & 48 & 60 & 60 & 63 & 56 & 45 \\
\hline \multicolumn{7}{|l|}{ Wetland dose $\left(\mathrm{W}-\mathrm{h} \mathrm{m}^{-2}\right)$} \\
\hline Mean & 14.7 & 18.9 & 16.5 & 20.8 & 22.6 & 27.9 \\
\hline SD & 4.5 & 5.6 & 5.8 & 4.8 & 4.1 & 2.1 \\
\hline \multirow[t]{2}{*}{ Range } & $3.6-20.7$ & $3.4-26.3$ & $6.8-24.5$ & $4.9-27.3$ & $11.3-29.7$ & $18.0-30.2$ \\
\hline & $A$ & $B$ & C & $D$ & $E$ & $F$ \\
\hline \multicolumn{7}{|l|}{ Wetland flux $\left(\mu \mathrm{W} \mathrm{cm}^{-2}\right)$} \\
\hline Mean & 90.9 & 124.4 & 111.3 & 132.5 & 154.0 & 171.0 \\
\hline SD & 28.0 & 36.7 & 39.5 & 30.6 & 28.0 & 12.7 \\
\hline \multicolumn{7}{|l|}{ [DOC] $\left(\mathrm{mg} \mathrm{L}^{-2}\right)$} \\
\hline Mean & 7.8 & 7.9 & 4.2 & 3.6 & 6.2 & 1.8 \\
\hline SD & 5.33 & 7.16 & 3.75 & 3.01 & 4.10 & 1.54 \\
\hline \multirow[t]{2}{*}{ Range } & $2.2-29.2$ & $0.6-36.7$ & $0.8-15.4$ & $0.6-17.0$ & $0.9-17.5$ & $0.7-7.3$ \\
\hline & $A$ & $A$ & $B$ & $B$ & $A$ & C \\
\hline \multicolumn{7}{|c|}{ Relative UV-B reduction $[\%$, mean (SD)]due to: } \\
\hline \multirow[t]{2}{*}{ Landscape } & $30.0(11.0)$ & $15.9(2.9)$ & $31.4(15.5)$ & $23.8(11.4)$ & $13.1(9.6)$ & $5.9(7.9)$ \\
\hline & $A$ & $C$ & $A$ & $B$ & $D$ & $E$ \\
\hline \multirow[t]{2}{*}{ DOC } & $30.6(16.2)$ & $27.8(20.8)$ & $23.7(18.2)$ & $15.5(12.1)$ & $23.4(17.6)$ & $8.7(3.9)$ \\
\hline & $A$ & $A, B$ & $B$ & C & $B$ & $D$ \\
\hline \multirow[t]{2}{*}{ DOC attenuation $\left(\mathrm{K}_{\mathrm{d}}, \mathrm{m}^{-1}\right)$} & $5.80(0.88)$ & $5.31(0.89)$ & $7.81(0.64)$ & $4.74(0.74)$ & $4.61(0.62)$ & $0.26(0.11)$ \\
\hline & $A$ & $B$ & C & $B$ & $B$ & $D$ \\
\hline
\end{tabular}

$U V-B$ dose values are for the summer solstice, for the day length indicated, and are estimated for a depth of $1 \mathrm{~cm}$ based on laboratory spectral absorbance scans. Rows containing letters indicate groupings resulting from means tests (ANOVA; Duncan, alpha $=0.05$ ) or from pairwise comparison of regression slopes for $K_{d,}$, lab $v$ s. DOC. Sample size for each park is provided in Table 1.

${ }^{a}$ Diffey dose means are for the 90 centile of values for 28 days centered on the summer solstice.

$11.8 \%$ among all parks. The wetland with the greatest reduction due to landscape is located in Olympic. ANOVA revealed significant differences in the effect of landscape on wetland UV-B dose between parks $(F=260.8, P<0.0001)$. Means tests (Duncan's multiple range test, with control for comparison-wise error rate) identified five distinct groupings; landscape reduced wetland UV-B dose equally in Smoky and Acadia relative to other parks and all other parks were dissimilar in the effect of landscape on UV-B dose.

The effect of DOC on UV-B dose (Table 2) was differentiated from the effect of landscape based on the product of the solar and proportionate transmittance spectra; this spectral product was integrated from 280 to $320 \mathrm{~nm}$ and multiplied by the day length to determine UV-B dose. Among all parks and wetlands, DOC reduced the subsurface UV-B dose by $1 \%-87 \%$. The average reduction due to DOC among all wetlands within a park ranged from $8.7 \%$ in Sequoia, to $31 \%$ in Acadia. Mean reduction was $28 \%$ in Glacier, $24 \%$ in Smoky, $23 \%$ in Rocky, and $16 \%$ in Olympic. ANOVA revealed significant differences in the effect of DOC on wetland UV-B dose between parks $(F=68.5, P<$ 0.001 ). Means tests (Duncan's multiple range test, with control for comparison-wise error rate) identified four distinct groups: DOC reduced wetland UV-B dose similarly in Acadia and Glacier, and in Glacier, Smoky, and Rocky (these two groups were dissimilar from one another), and DOC reduced wetland UV-B less in Olympic and Sequoia relative to other parks (DOC effects in these parks were also statistically dissimilar from one another).

A negative relationship between DOC concentration and the attenuation of UV-B flux (estimated as $K_{d, \text { lab }}$ ) was evident in all parks (Figure 3), except for Sequoia. Regression $r^{2}$ values ranged from 0.11 in Sequoia to 0.89 in Glacier. All regressions, except that for Sequoia wetlands, were significant $\left(P=0.0001\right.$ or smaller). The Sequoia wetlands $r^{2}$ value $(0.011)$ was considerably lower than that of the other parks. Pairwise comparison of the slope parameters indicated that Glacier, Olympic, and 

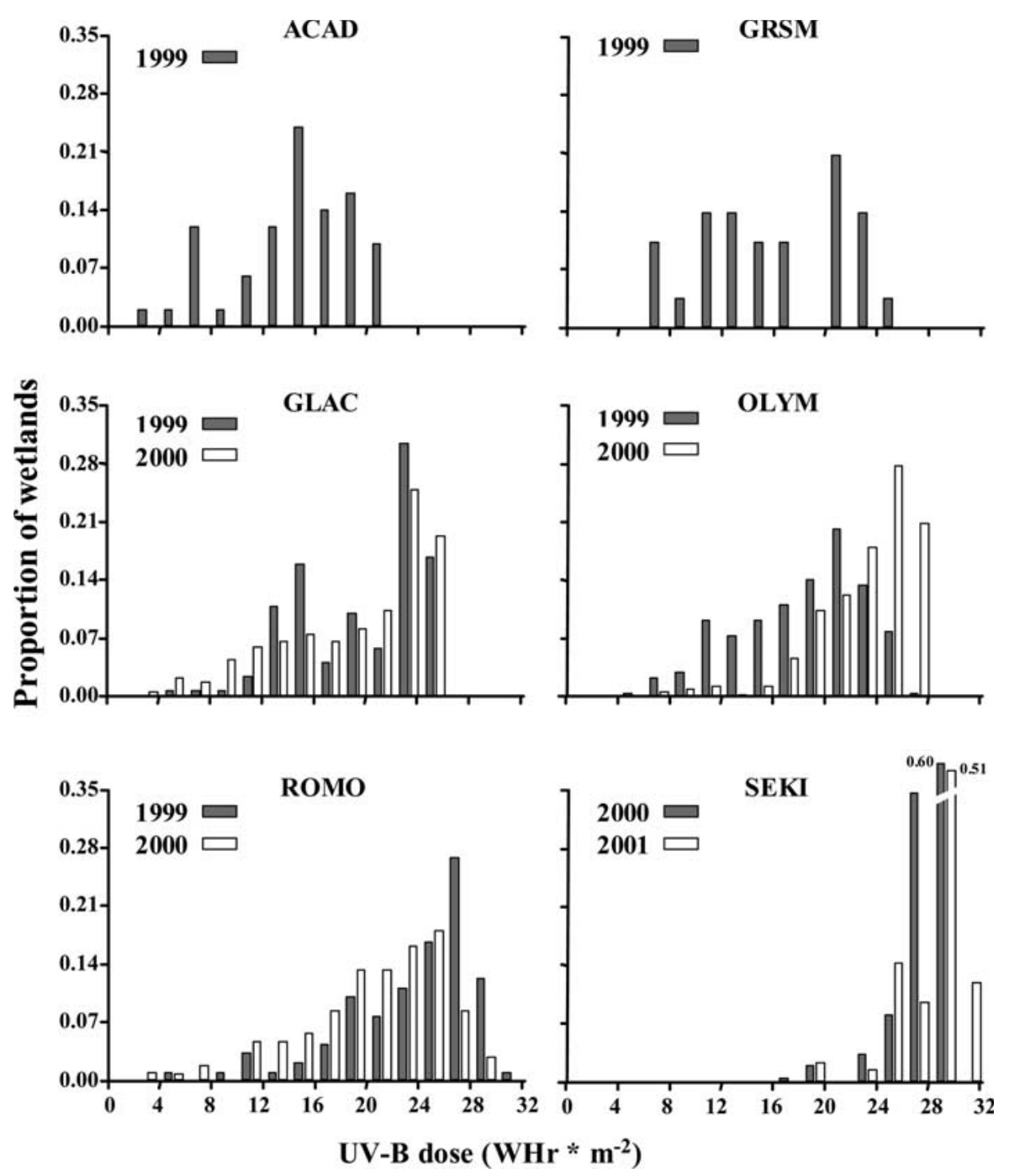

Figure 2. Frequency distribution of UV-B doses (1024) estimated for all wetlands in six national parks between 1999 and 2001 (analytical $N$ values for parks are listed in Table 1, and proportions are calculated for each year of sampling).

Rocky were not different from one another, but all were different from Acadia and Sequoia, which were also significantly different from one another (Table 2).

Attenuation coefficients calculated from spectrophotometric scan data, $K_{d, \text { lab }}$, were compared with attenuation coefficients generated from fieldcollected values, $K_{\text {d,field }}$ (Figure 4 ). The results suggest that field attenuation values can be estimated from laboratory spectrophotometric scans; $K_{d, \text { field }}=K_{d, \text { lab }} 0.96+8.6, r^{2}=0.71$ ), although considerable variability was apparent at higher attenuation values (Figure 4).

The relationships between estimated UV-B doses and action spectra (or biological weighting function) doses were very consistent (Figure 5). Regression $r^{2}$ values for these relationships were greater than 0.99 for both Setlow's DNA and erythemal action spectra, and 0.97 for inhibition of photosynthesis. The relationship of UV-B, UV-A, and visible (wavelengths from 400 to $700 \mathrm{~nm}$ ) radiation to total radiation (280-700 nm) were also very consistent among all parks and wetlands; the mean percentage of total estimated radiation $(280-700 \mathrm{~nm})$ was $0.46 \%$ $(\mathrm{Se}=0.0024)$ for UV-B, $11.3 \%(\mathrm{Se}=0.032)$ for UV$\mathrm{A}$, and $89.4 \%$ ( $\mathrm{Se}=0.029)$ for visible-range radiation.

Between-year variability in the relationship between DOC and UV-B dose was evaluated by comparing doses estimated for Glacier wetlands that were visited in both 1999 and 2000. The analysis was limited to wetlands where the date of sampling differed between years by no more that 


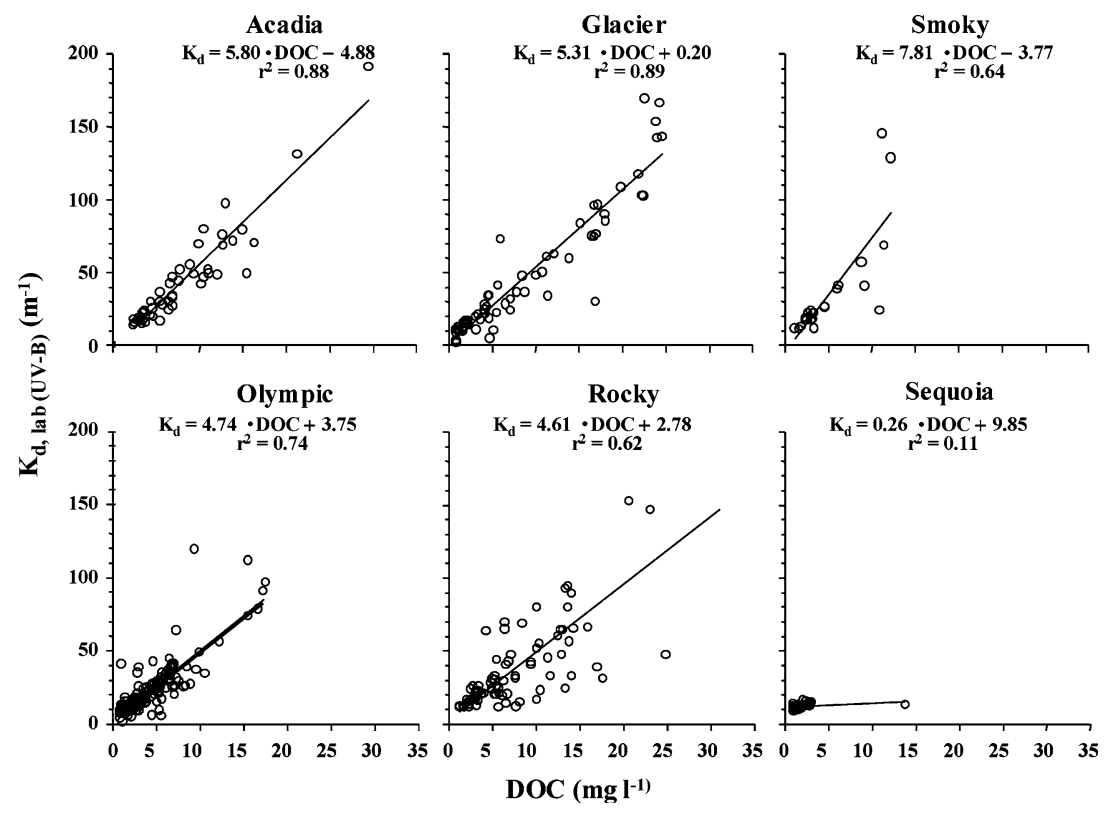

Figure 3. The relationship between $K_{d \text {,lab }}$ and DOC concentration for all wetlands and sampling years in each park. $K_{d}$, lab are estimates based on laboratory attenuation measurements.

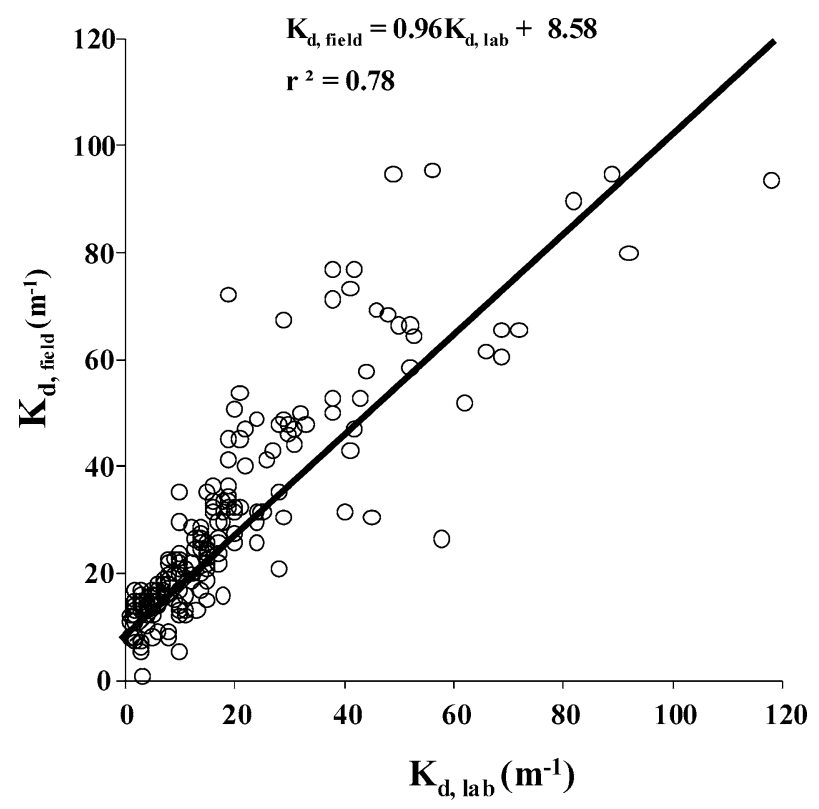

Figure 4. The relationship between attenuation coefficients derived from field-collected $\left(K_{d, \text { field }}\right)$ and laboratory-derived $\left(K_{d,}\right.$ lab $)$ data. Analytical $N$ : Acadia $=51$, Glacier $=21$, Smoky $=7$, Rocky $=112$, Sequoia $=40$.

28 days. Variability in the dose estimates was based only on spectral scans of DOC for each year, all other factors were identical. Estimates from 2000 for each wetland were regressed with the same estimates from 1999. Two regressions were completed to discern the relative importance of DOC variability: one incorporated only the effect of DOC on dose $\left(y 2000=y 1999 \times 0.68+6.34, r^{2}=0.72\right)$, the other incorporated the effect of DOC and landscape on dose $(\mathrm{y} 2000=\mathrm{y} 1999 \times 0.78+3.61$, $\left.r^{2}=0.82\right)$. The improved fit of the latter regression provided an indication of the relative importance of DOC when all other factors were included in dose estimation.

Within-year variability in the relationship between DOC and UV-B dose was assessed graphically (Figure 6) by plotting dose estimates for each replicate visit in wetlands from Rocky, Olympic, and Glacier. It is clear from this plot that doses estimated for each of these dates would vary considerably for some of the visited wetlands. In Rocky and Glacier, this variation can approach approximately $90 \%$ and $50 \%$, respectively, and averaged $19.6 \%$ among all revisited wetlands. Variation in DOC and its relationship to UV transmittance in wetland water columns is discussed in greater detail by Brooks and others (this issue).

\section{Discussion}

Two major determinants of UV-B dose in wetlands were incorporated into the dose estimates presented here. Both shading by topographic and large vegetative features and DOC concentration and composition combined to produce nearly an orderof-magnitude range of dose values across all wetlands (3.4-32.1 W-h m ${ }^{-2}$ ), and a maximum range in a single park (Glacier) of $4.4-32.1 \mathrm{~W}-\mathrm{h} \mathrm{m}^{-2}$. The effect of landscape features on UV-B dose was as dramatic as attenuation by DOC in the $1-\mathrm{cm}$ water column. Among all parks and wetlands, landscape 


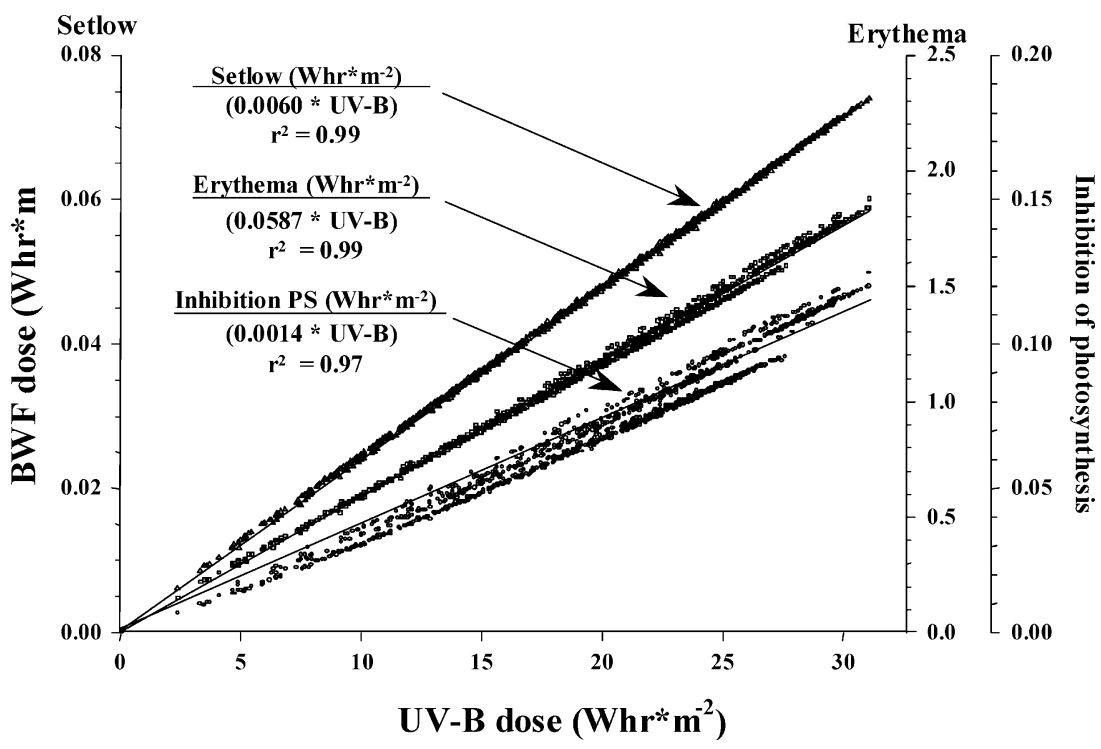

Figure 5. The relationship between UV$\mathrm{B}$ dose and BWF function doses for Setlow DNA damage, erythema, and inhibition of photosynthesis. Equations are best-fit lines (forced through the origin) derived from regression analyses.

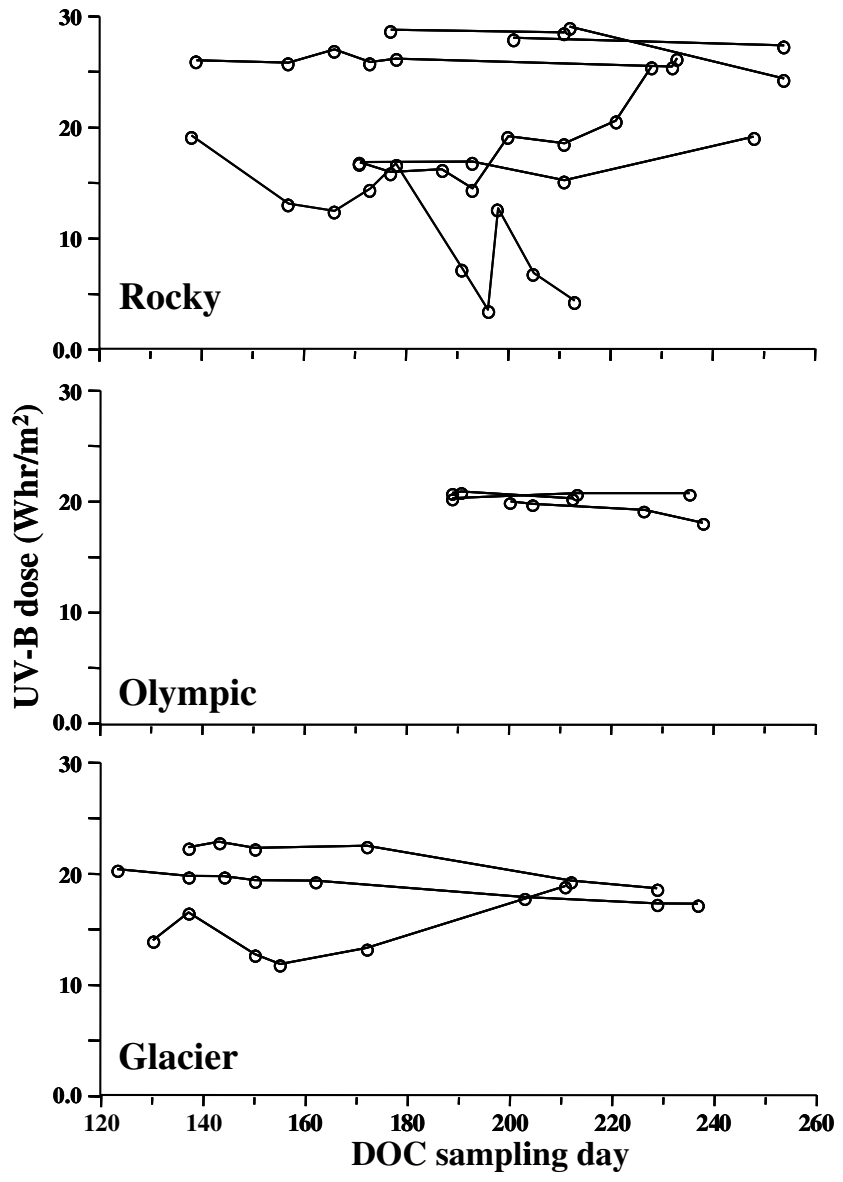

Figure 6. UV-B dose estimates for 13 wetlands sampled several times during a single season. All doses are based on summer solstice spectrum.

alone reduced UV-B dose by zero to $77 \%$. Reduction by DOC (estimated for a $1-\mathrm{cm}$ water depth) ranged from $1 \%$ to $87 \%$, and averaged $11.9 \%$ among all wetlands and parks.

This level of reduction by shading elements in the environment has been noted in many studies (for example, Bushing 1996; Rader and Belish 1997; Parsons and others 1998) but has not previously been estimated for small wetlands. Literature descriptions of field UV-B experiments have generally not included estimates of UV-B doses but rather have been limited to comparative flux estimates for various treatment levels (for example, Blaustein and others 1995; Hays and others 1996; Anzalone and others 1996; Halac and others 1997; Rader and Belish 1997; Kiesecker and others 2001; Leech and Williamson 2001), with little or no description of local landscape. Although these values are useful for comparing treatments within experiments, they do not provide information sufficient for estimating the risk associated with UV-B exposure at other locations, particularly where landscape shading is relatively high and biological effects have not been characterized. It is also useful to note that where UV-B doses were carefully measured (Ankley and others 1998, 2000; Tietge and others 2001; Diamond and others 2002), reduction of UV-B dose equivalent to the mean measured for all parks in this study $(11.9 \%)$ would be sufficient to eliminate the effects detected. The comparability of UV-B dose reduction for landscape and DOC demonstrate that these factors are of equal importance in describing the risk associated with changing UV-B in the environment.

The relationship between DOC concentration and attenuation coefficients $\left(\mathrm{K}_{d, \text { lab }}\right)$ varied among parks. This variability was examined by comparing 
the slope parameter for regressions of $\mathrm{K}_{d \text {,lab }}$ versus DOC concentration for each park. The slope of the regression equation defines the rate, within the water column, at which UV-B radiation is reduced per unit DOC. Significant differences in the slope suggest functional and probably structural differences in DOC between parks. In this analysis, intercepts were fixed so that only slopes were statistically compared. The slope of regressions for Glacier $\left(-5.31 \mathrm{~m}^{-1}\right)$, Olympic $\left(-4.74 \mathrm{~m}^{-1}\right)$, and Rocky $\left(-4.61 \mathrm{~m}^{-1}\right)$ were not different from one another, but all were different from regression slopes for Acadia $\left(-5.80 \mathrm{~m}^{-1}\right)$ and Smoky $(-7.81$ $\mathrm{m}^{-1}$ ), which were also different from one another. The regression of attenuation coefficients against DOC concentrations was not significant for wetlands in Sequoia. This is not surprising given the extremely low DOC levels found in Sequoia wetlands. These results indicate that variability in DOC composition between parks (or perhaps regions) results in significant differences in UV-B attenuation properties.

The relationship of DOC and UV-B penetration has received a great deal of attention (for example, Baker and Smith 1982; Williamson and others 1996; Arst and others 1997; Morris and Hargreaves 1997; Jerome and Bukata 1998; Peterson and others 2002). A general conclusion from these studies is that DOC concentration is the single most consistent predictor of UV-B attenuation in the water column, although in some low-DOC systems chlorophyll, algae, and other factors can be significant predictors as well (Smith and others 1999; Laurion and others 2000). In the present study, the relationship between DOC and UV-B attenuation (that is, the slope parameter from regression analyses) ranged from 4.74 (Olympic) to 7.81 (Smoky). This relationship has been described for a variety of lakes and ponds, and DOC is generally reported to be less effective at attenuating UV-B compared to our values. For example, Peterson and others (2002) reported slopes of 2.10 for their data, 1.98 for Arts and others (2000) data, and 1.43 for Crump and others (1999) data. Scully and Lean (1994) similarly reported a slope value of 2.65 for this relationship. The difference between our estimates and these other estimates likely derives from methodological differences, including DOC analyses and the fact that our attenuation values are derived from laboratory absorbance data rather than field measurement of $K_{d}$. The relationship between $K_{d \text {,lab }}$ and $K_{d \text {,field }}$ has been investigated by other researchers using regression analyses. Lean (1998) estimated a slope of 1.22 (based on measurements at $310 \mathrm{~nm}$ ), Morris and Hargreaves (1997) estimated a slope of
1.27 (based on measurements at $320 \mathrm{~nm}$ ), Crump and others (1998) estimated a slope of 0.93 (based on measurements at $310 \mathrm{~nm}$ ). Our slope estimate, integrated across the UV-B range, is 0.96, within the range of these reported values.

The variation in the $\mathrm{DOC}-\mathrm{K}_{d}$, lab relationship between wetlands in different parks does not seem to be related to differences in the spectral nature of the absorbance curves for the various waters. One indication that this is true is the very consistent relationship between the estimated UV-B dose and the three BWF doses calculated (see Figure 5). If the variation in UV-B doses for similar DOC concentrations was due to spectral differences, then one would expect to see variation in UV-B/BWF relationships of similar magnitude. This is particularly true for the Setlow DNA action spectrum, which is particularly sensitive to variation in the shorter UV-B wavelengths. Additional evidence that spectral differences do not account for the variation in UV-DOC relationships is provided by the spectrophotometric scan data. Sample data were selected from Acadia, Glacier, Smoky, Rocky, and Olympic to encompass a narrow range of DOC concentrations (10.3-11.3 $\left.\mathrm{mg} \mathrm{L}^{-1}\right)$. The UV-B dose estimates for these wetlands ranged from 6.0 to 14.2 $\mathrm{W}-\mathrm{h} \mathrm{m} \mathrm{m}^{-2}$. The shape of the transmittance curves for these samples is very similar, suggesting that the variation in UV-B dose is related to bulk absorbance rather than to spectral variation among the wetlands.

Among the six parks studied, UV-B doses were clearly highest in Sequoia. The effect of both of the major factors incorporated into dose estimation, shading due to landscape and DOC $(5.9 \%$ and $8.7 \%$ reductions from possible maxima, respectively), was low, relative to other parks (Table 2). UV-B doses were also relatively high in Rocky and Olympic, whereas the other three parks had lower UV-B doses. Despite the wide variation in dose among, and within, all parks, it is clear that the higher-elevation parks, where reduced vegetation results in less shading (or reduction of diffuse irradiance) as well as reduced carbon inputs to wetlands, have the highest UV-B doses. This effect is balanced, to some extent, by the presence of large geographic features that can also reduce direct and diffuse irradiance, although it is apparent from these data that this effect is less than the factors just described. Higher elevation also contributes to higher doses due to the shorter atmospheric pathlength traversed by incoming solar radiation. The effect of elevation was incorporated in Solar Analyst models from DEMs and was not quantitatively separated from other landscape effects. 
The accuracy of the UV-B dose estimates presented here cannot be evaluated in a fully quantitative manner. Although the Brewer UV-B data provide excellent ground-level UV-B estimates (for the Brewer instrument location) and have been compared extensively with satellite and other UV-B data (Sobt and others 2002), there presently are no wetland UV-B dose estimates available (excepting Diamond and others 2002) for comparison with our results. It is possible, however, to evaluate the accuracy of the SBDART and Solar Analyst modeling approach by estimating Diffey UV doses for each Brewer site and then comparing the results with the clear-sky maxima derived from each of the Brewer instruments. This is a particularly valid approach to ground-truthing these methods given that the degree of obstruction of the local horizon varies considerably among the Brewer locations (for example, the Sequoia Brewer is located in a river valley surrounded by ridges and peaks with elevations on the order of 700-800 $\mathrm{m}$ above the Brewer installation). The highest $5 \%$ of all Brewer estimates for each park was compared to estimates generated using the Solar Analyst and SBDART models as implemented for study wetlands. The closest agreement between these highest, clear-sky, measured and modeled values occurred in Glacier where the mean Brewer value was $5690.7 \mathrm{~J}(\mathrm{SD}=87.18)$ and the modeled estimate was $5688.9 \mathrm{~J}$, a $0.03 \%$ difference. The largest discrepancy occurred in Smoky where the mean Brewer value was 6070.1 J $(S D=198.02)$ and the modeled estimate was $6500.7 \mathrm{~J}$, a $7.09 \%$ difference. These values were $5076.9 \mathrm{~J}(\mathrm{SD}=81.72)$ vs. $5014 \mathrm{~J}$, a difference of $1.23 \%$ for Acadia; 5084.1 $\mathrm{J}(\mathrm{SD}=203.11)$ vs. $5258.7 \mathrm{~J}$, a difference of $3.43 \%$ for Olympic; $7592.4 \mathrm{~J}$ (SD = 123.54) vs. $7466.6 \mathrm{~J}$, a difference of $1.66 \%$ for Rocky; and $6054.5 \mathrm{~J}$ $(\mathrm{SD}=126.36)$ vs. $6116.6 \mathrm{~J}$, a difference of $1.03 \%$ for Sequoia. During earlier iterations of this work, dose was estimated for the Sequoia Brewer location using a DEM that had been manipulated to remove all topographic features. This yielded a dose value of $9269.9 \mathrm{~J}$ and indicates that landscape features at that location reduce dose by approximately $34 \%$, and that the modeling process generally accurately incorporates landscape effects.

The accuracy of the dose estimates presented here can also be evaluated by comparison with UVB doses recently reported for northern Midwest wetlands by Diamond and others (2002). These estimates, derived for use in a risk assessment of UV-B effects, were calculated in a manner similar to those presented here, with the major difference that landscape features were not included in the Midwest estimates, whereas historical weather data were included. In that study, weather (cloudiness) reduced clear-sky doses by an average of approximately $26 \%$; in the present study, landscape reduced potential maximum doses by an average of approximately $12 \%$. The mean dose for all Midwest wetlands studied by Diamond and others (2002), at a depth of $1 \mathrm{~cm}$ (1-cm-depth results not reported), was $11.7 \mathrm{~W}-\mathrm{h} \mathrm{m}^{-2}$. Considering the $13 \%$ difference in reduction values between weather (incorporated by Diamond and others 2002) and landscape effects (used in this study), this value accords well with the mean dose for Acadia wetlands (14.7 W-h m ${ }^{-2}$ ) which are at similar latitude and elevation.

The usefulness of the ground-level radiometric UV measurements for corroborating these UV dose estimates is limited by several factors. First, broadwaveband radiometric instruments are notoriously inaccurate, particularly for the UV-B wavelength range (although their precision can be very reliable). Second, all measurements made in this research were of irradiance rather than dose; no effort was made at any location to log data over a long period of time. Third, measurements were made at different times of the day and season at each wetland and it would be very difficult to adjust each measurement accordingly. Accurately ground-truthing these estimates would require the installation of expensive, elaborate, and large spectroradiometric instruments at just a few locations. Given the scope of this study, this type of ground-truthing was necessarily limited to the Brewer instrument data.

The uncertainty of the dose estimates presented here is also affected by temporal variation in DOC concentration, composition, and capacity to absorb UV-B (Brooks and others, this issue), and the limited conditions for which estimates were made. The extent of variability in the effect of DOC on UV-B ranged from zero to $90 \%$ for wetlands that were revisited at various time intervals, either during a single year (Figure 6) or over two years. The average difference between the highest and lowest UV-B doses (calculated to represent only the effect of DOC) for these repeat visits was approximately $20 \%$. This variability is somewhat of an overestimation, as differences in UV-B dose are also strongly controlled by landscape factors that are much less variable over the breeding season. The actual effect of DOC variation relative to landscape effects was apparent when dose estimates for wetlands visited in Glacier in 2000 were regressed against the same values for 1999 . The regression $r^{2}$ estimate improved from 0.72 to 0.82 when landscape effects were included in the dose estimation. These values give an indication of potential vari- 
ability in dose estimation. However, because the number of revisited wetlands was small, this variability was not incorporated into a formal uncertainty estimation for doses at all wetlands. No attempt was made to incorporate various weather conditions (as in Diamond and others 2002) or variability in water column factors, other than DOC that can significantly affect attenuation, including suspended material and algae. Although a global correction for weather could be applied to each park, based on regional cloud-cover data, this would not reduce the uncertainty of the estimations given the considerable variability in microclimate in mountainous areas. Also, the watercolumn, UV-attenuating factors other than DOC tend to be episodic and thus difficult to measure but are also effective for fairly short time periods.

Despite the limitations of the values presented here, we believe they represent a significant advance in UV dosimetry, particularly where information on UV exposure is required for many locations. These data provide model estimates against which field-collected dose information can be compared in the future. This approach also provides a means to predict future UV-B exposure in a variety of aquatic habitats and locations given potential alteration of landscape, DOC processes, or other ecological factors. Ultimately, the goal of this effort was to provide UV-B dose estimates directly applicable to preliminary analyses of the relationship between UV-B doses and amphibian distributions in selected locations across North America (Adams and others this issue).

\section{ACKNOWLEDGEMENTS}

This work could not have been completed without the dedicated effort of field team leaders, Elizabeth Ballenger, Rebecca Chalmers, Jodi Garton, Karen Holzer, Heidi Kloeppel, Lisa McKeon, Carlie Ronca, and Meryl Rose, and chemical analyses by Terri Jicha, Lisa Frederick, Colleen Elonen, and Lee Anderson. This work was funded under the EPA's PRIMENet (Parks Research and Intensive Monitoring of Ecosystems Network) program. The work described in this document has been funded wholly (or in part) by the U.S. Environmental Protection Agency. It has been subjected to review by the National Health and Environmental Effects Research Laboratory and approved for publication. Approval does not signify that the contents reflect the views of the Agency nor does mention of trade names or commercial products constitute endorsement or recommendation for use.

\section{REFERENCES}

Adams MJ, Hossack BR, Knapp RA, Corn PS, Diamond SA, Trenham PC, Fagre DB. 2005. Distribution patterns of lenticbreeding amphibians in relation to ultraviolet radiation exposure in western North America. Ecosystems 8:00-00.

Ankley GT, Tietge JE, DeFoe DL, Jensen KM, Holcombe GW, Durhan EJ, Diamond SA. 1998. Effects of ultraviolet light and methoprene on survival and development of Rana pipiens. J E Toxicol Chem 17:2350-542.

Ankley GT, Tietge JE, Holcombe GW, DeFoe DL, Diamond SA, Jensen KM, Degitz SJ. 2000. Effects of laboratory ultraviolet radiation and natural sunlight on survival and development of Rana pipiens. Can J Zool 78:1092-100.

Ankley GT, Diamond SA, Tietge JE, Holcombe GW, Jensen KM, DeFoe DL, Peterson R. 2002. Assessment of the risk of solar ultraviolet radiation to amphibians. I. Dose-dependent induction of hindlimb malformations in the northern leopard frog (Rana pipiens). Environmental Science and Technology 36:2853-58.

Anzalone CR, Kats LB, Gordon MS. 1996. Effects of solar UV-B radiation on embryonic development in Hyla cadavera, Hyla regilla, and Taricha torosa. Conservation Biology 12:646-53.

Arst H, Maekivi S, Lukk T, Herlevi A. 1997. Calculating irradiance penetration into water bodies from the measured beam attenuation coefficient. Limnol Oceanogr 42:379-85.

Arts MT, Robarts RD, Kasai F, Waiser MJ, Tumber VP, Plante AJ, Rai H, De Lange HJ. 2000. The attenuation of ultraviolet radiation in high dissolved organic carbon waters of wetlands and lakes in the northern Great Plains. Limnol and Oceanogr 45:292-99.

Baker KS, Smith RC. 1982. Spectral irradiance penetration in natural waters. In: Calkins J, Ed. The role of solar ultraviolet radiation in marine ecosystems. New York: Plenum. p 223-46.

Baucher NP, Prezelin BB. 1996. An in situ biological weighting function for UV inhibition of phytoplankton carbon fixation in the Southern Ocean. Mar Ecol Progr Ser 144:223-36.

Blaustein AR, Wake DB, Sousa WP. 1994a. Amphibian declines: judging stability, persistence, and susceptibility of populations to local and global extinctions. Conserv Biol 8:60-71.

Blaustein AR, Hoffman PD, Hokit DG, Kiesecker JM, Walls SC, Hays JB. 1994b. UV repair and resistance to solar UV-B in amphibian eggs: A link to population declines? Proc Natl Acad Sci 91:1791-5.

Blaustein AR, Edmond B, Kiesecker JM, Beatty JJ, Hokit DG. 1995. Ambient ultraviolet radiation causes mortality in salamander eggs. Ecol Appl 5:740-3.

Blaustein AR, Kiesecker JM, Hoffman PD, Hays JB. 1997. The significance of ultraviolet-B radiation to amphibian population declines. Rev Toxicol 1:147-65.

Blumthaler M, Ambach W, Salzgeber M. 1994. Effects of cloudiness on global and diffuse UV irradiance in a highmountain area. Theoret Appl Climatol 50:25-30.

Brooks PD, O’Reilly CM, Diamond SA, Campbell DH, Knapp R, Bradford D, Corn PS, Hossack B, Tonnessen K. 2005. Spatial and temporal variability in the amount and source of dissolved organic carbon: Implications for UV exposure in amphibian habitats. Ecosystems. 8:00-00.

Bushing WW. 1996. The influence of island topography on the nearshore light regime and the distribution of giant kelp around Santa Catalina island. ESRI User Conference Paper No. 335 . 
Crump D, Lean D, Berrill M, Coulson D, Toy L. 1998. Tracking the propagation of solar ultraviolet radiation: Dispersal of ultraviolet photons on inland waters. Journal of Great Lakes Res 24:666-80.

Crump D, Lean D, Berrill M, Coulson D, Toy L. 1999. Spectral irradiance in pond water: influence of water chemistry. Photochem Photobiol 70:893-901.

Diamond SA, Peterson GS, Tietge JE, Ankley GT. 2002. Assessment of the risk of solar ultraviolet radiation to amphibians. III. Prediction of impacts in selected northern midwestern wetlands. Environ Sci Technol 36: 2866-74

Diffey B. 1995. Monitoring personal exposure to solar ultraviolet radiation. In: Zerofos CS, Alkiviadis FB, Eds. Solar ultraviolet radiation: modeling, measurement and effects. Berlin: Springer-Verlag. p 187-200.

Dubayah RC. 1994. Modeling a solar radiation topoclimatology for the Rio Grande River Basin. J Vegetat Sci 5:627-40.

Dubayah R, Rich PM. 1995. Topographic solar radiation models for GIS. Int J Geogr Inf Sys 9:405-19.

Dubayah R, Rich PM. 1996. GIS-based solar radiation modeling. In: Goodchild MF, Steyaert LT, Parks BO, Johnston C, Maidment D, Crane M, Glendinning S, eds. GIS and environmental modeling: progress and research issues. Fort Collins, CO: GIS World Books. p 129-134.

Grant RH. 1991. Ultraviolet and photosynthetically active bands: plane surface irradiance at corn canopy base. Agron J 83:396401.

Green AES, Shippnick PF. 1982. UV-B reaching the surface. In: Calkins J, Eds. The role of solar ultraviolet radiation in marine ecosystems. New York: Plenum. p 5-28.

Hader DP, Kumar HD, Smith RC, Worrest RC. 1998. Effects on aquatic ecosystems. J Photochem Photobiol B Biol 46:5368.

Halac S, Felip M, Camarero L, Sommaruga-Wograth S, Psenner R, Catalan J, Sommaruga R. 1997. An in situ enclosure experiment to test the solar UVB impact on plankton in a high-altitude mountain lake. I. Lack of effect on phytoplankton species composition and growth. J Plankton Res 19:1671-86.

Hays JB, Blaustein AR, Kiesecker JM, Hoffman PD, Pandelova I, Coyle D, Richardson T. 1996. Developmental responses of amphibians to solar and UVB sources: A comparative study. Photochem Photobiol 64:449-56.

Hetrick WA, Rich PM, Barnes FJ, Weiss SB. 1993. GIS-based solar radiation flux models. Am Soc Photogrammetry Remote Sens Tech Papers 3:132-43.

Jerlov NG. 1976. Marine optics. Elsevier Oceanography Series 14. Amsterdam:Elsevier.

Jerome JH, Bukata RP. 1998. Tracking the propagation of solar ultraviolet radiation: dispersal of ultraviolet photons in inland waters. J Great Lakes Res 24:666-90.

Jerome JH, Bukata RP, Bruton JE. 1988. Utilizing the components of vector irradiance to estimate the scalar irradiance in natural waters. Appl Optics 27:4012-8.

Karentz D, Lutz LH. 1990. Evaluation of biologically harmful ultraviolet radiation in Antarctica with a biological dosimeter designed for aquatic environments. Limnol Oceanog 35:54961.

Kiesecker JM, Blaustein AR. 1995. Synergism between UV-B radiation and a pathogen magnifies amphibian embryo mortality in nature. Proc Natl Acad Sci 92:11049-52.
Kiesecker JM, Blaustein AW, Belden LK. 2001. Complex causes of amphibian population declines. Nature 410:681-3.

Kirk JTO. 1994. Optics of UV-B radiation in natural waters. Arch Hydrobiol Beih Ergeb Limnol 43:1-16.

Laurion I, Warwii FI, Lean DRS. 1997. Underwater ultraviolet radiation: Development of spectral models for northern high latitude lakes. Photochem Photobiol 65:107-14.

Lean D. 1998. Attenuation of solar radiation in humic waters. In: Hessen DO, Tranvik LJ, Eds. Aquatic humic substances: ecology and biogeochemistry. London: Springer. $p$ 109-24.

Leech DM, Williamson CE. 2001. In situ exposure to ultraviolet radiation alters the depth distribution of Daphnia. Limnol Oceanog 46:416-20.

Madronich S. 1993. The atmosphere and UV-B radiation at ground level. In: Young AR, Bjorn LO, Moan J, Nultsch W, Eds. Environmental UV photobiology. New York: Plenum. p $1-35$.

Madronich S, Flocke S. 1997. Theoretical estimation of biologically effective UV radiation at the earth's surface. In: Zerofos CS, Bais AF, Eds. Solar ultraviolet radiation: modeling, measurement, and effects. Berlin: Springer-Verlag. p 23-48.

McKinlay AF, Diffey BL. 1987. A reference spectrum for ultraviolet induced erythema in human skin. In: Passchler WR, Bosnajokovic BFM, eds. Human exposure to ultraviolet radiation: risks and regulations. Amsterdam: Elsevier. $p$ 83-87.

Morris DP, Hargreaves BR. 1997. The role of photochemical degradation of dissolved organic carbon in regulating the UV transparency of three lakes on the Pocono Plateau. Limnol Oceanogr 42:239-49.

Morris DP, Zagarese H, Williamson CE, Balsiero EG, Hargreaves BR, Modenutti B, Moeller R, Queimalinos C. 1995. The attenuation of solar UV radiation in lakes and the role of dissolved organic carbon. Limnol Oceanogr 40:1381-91.

Nagl AM, Hofer R. 1997. Effects of ultraviolet radiation on early larval stages of the alpine newt, Triturus alpestris, under natural and laboratory conditions. Oecologia 110:514-9.

Palen WJ, Schindler DE, Adams MJ, Pearl CA, Bury RB, Diamond SA. 2002. Optical characteristics of natural waters protect amphibians from UV-B in the U.S. Pacific Northwest. Ecology 83:2951-7.

Parisi AV, Kimlin MG, Wong JCF, Wilson M. 2000. Diffuse component of solar ultraviolet radiation in tree shade. $\mathrm{J}$ Photochem Photobiol B Biol 54:116-120.

Parsons PG, Neale R, Wolski P, Green A. 1998. The shady side of solar protection. Med J Aus 168:327-30.

Peterson GS, Johnson LB, Axler RP, Diamond SA. 2002. In situ characterization of solar ultraviolet radiation in amphibian habitats. Environ Sci Technol 36:2859-65.

Pounds JA. 2001. Climate and amphibian declines. Nature 410:639-40.

Rader RB, Belish TA. 1997. Effects of ambient and enhanced UV$B$ radiation on periphyton in a mountain stream. J Freshwater Ecol 12:615-28

Rich PM, Hetrick WA, Saving SC. 1995. Modeling topographic influences on solar radiation: a manual for the Solarflux model. Los Alamos National Laboratory Report.

Ricchiazzi P, Yang S, Gautier C, Sowle D. 1998. SBDART: A research and teaching software tool for plane-parallel radiative transfer in the earth's atmosphere. Bull Am Meteorol Soc 79:2101-14 
Robinson N. 1966. Solar Radiation. Amsterdam: Elsevier.

Rostan JC, Cellot B. 1995. On the use of UV spectrophotometry to assess dissolved organic carbon variation in the Upper Rhone River. Aquat Sci 57:70-80.

Sabburg J, Kimlin MG, Rives JE, Meltzer RS, Taylor TE, Schmalzle G, Zheng S, Huang N, Wilson AR, Udelhofen PM. 2002. Comparisons of corrected daily integrated erythemal UVR from the U.S. EPA/UGA network of Brewer spectroradiometers with model and satellite data. Proc SPIE Int Soc Opt Eng 4482:70-81.

Setlow RB. 1974. The wavelengths in sunlight effective in producing skin cancer: A theoretical analysis. Proc Natl Acad Sci 71:3363-3366

Scully NM, Lean DRS. 1994. The attenuation of ultraviolet radiation in temperate lakes. Arch Hydrobiol Beih Ergebn Limnol 43:135-144.

Smith REH, Furgal JA, Charlton BM, Greenberg BM, Hiriart V, Marwood C. 1999. Attenuation of ultraviolet radiation in a large lake with low dissolved organic matter concentrations. Can J Fish Aquat Sci 56:1351-61.
Stamnes K, Tsay S, Wiscombe W, Jayaweera K. 1988. Numerically stable algorithm for discrete-ordinate-method radiative transfer in multiple scattering and emitting layered media. Appl Optics 27:2502-9.

Tietge JE, Diamond SA, Ankley GT, DeFoe DL, Holcombe GW, Jensen KM, Degitz SJ, Elonen GE, Hammer E. 2001. Ambient solar UV radiation causes mortality in larvae of three species of Rana under controlled exposure conditions. Photochem Photobiol 74:261-8.

UNEP. 1998. Environmental effects of ozone depletion: 1998 assessment. Nairobi: United Nations Environment Programme.

U.S. Standard Atmosphere. 1976. NOAA-S/T76-1562. Washington, D.C: U.S. Govternment Printing Office.

Williamson CE, Stemberger RS, Morris DP, Frost TM, Paulsen SG. 1996. Ultraviolet radiation in North American lakes: attenuation estimates from DOC measurements and implications for plankton communities. Limnol Oceanogr 41:1024-34.

Young AR, Bjorn LO, Moan J, Nultsch W. 1993. Environmental UV Photobiology New York: Plenum. 